\title{
Lost \& Found: the importance of good practices in security matters
}

\author{
A. M. Batalla Gonzalez, L. F. Cueva Castro, M. M. Bastitta, J. M. Gil Sanchez, \\ M. Rodriguez Prieto, M. V. Moral Garcia \\ Hospital de la Santa Creu I Sant Pau - Barcelona (Spain)
}

\section{Background}

Patient safety is one of the most pressing challenges in health care. One estimate says that one case of a retained item occurs at least once a year in a major hospital where 8000 to 18,000 major cases are carried out each year (1).

\section{Case Report}

77 year-old women, with a biologic aortic valve substitution by mini-sternotomy approach. In the Figure 1 you can see the postoperative Chest X-Ray. The cardiac surgery team asked for Chest CT to confirm diagnosis and decide the surgical approach (sternotomy vs toracotomy), but no forceps where found in the Chest CT, but they still appear in the X ray. We decided to remove the wound dressing, finding that the forceps where a false image caused by "x ray detectable swabs" (Figure2)

\section{Figure 1}

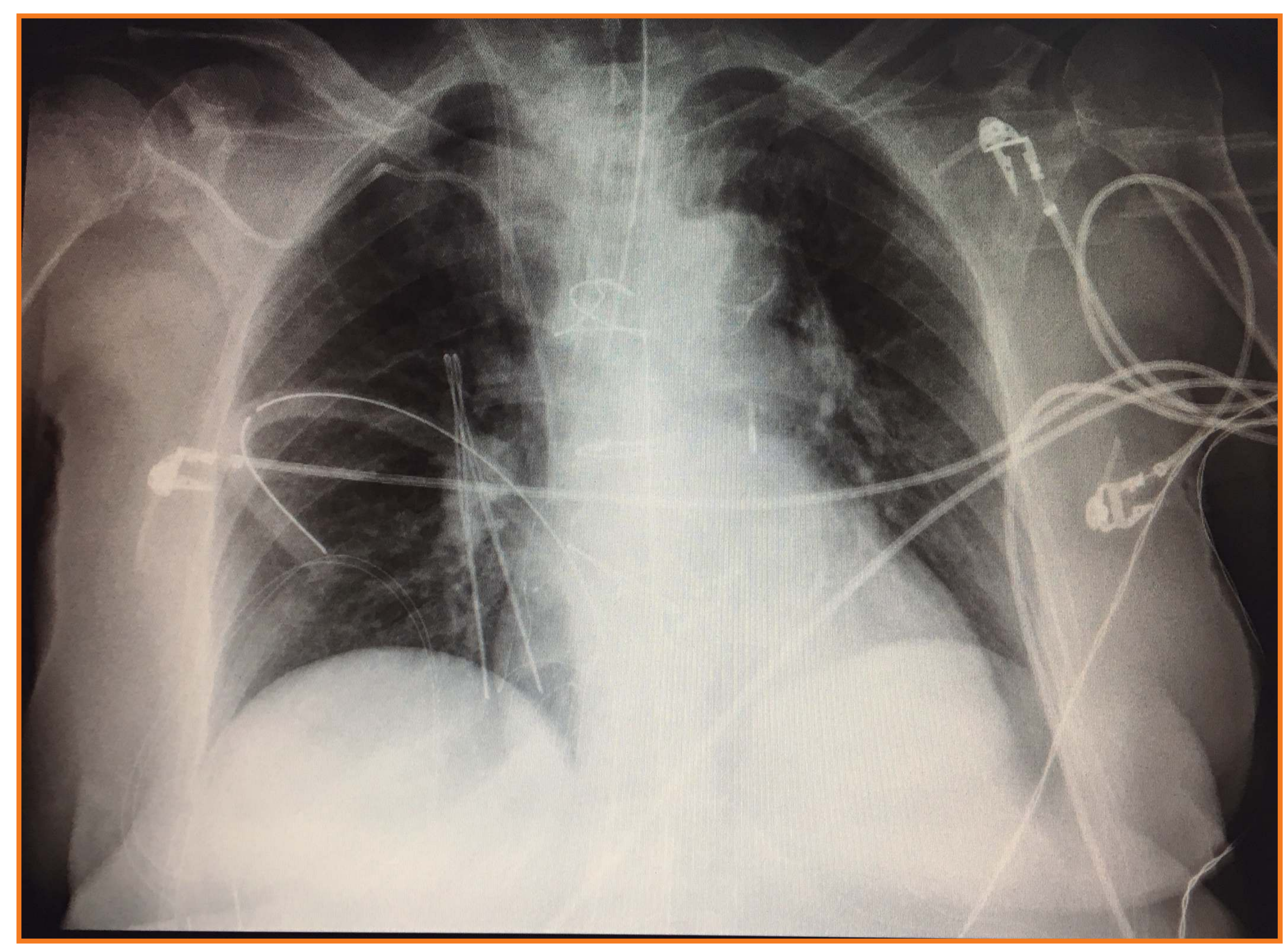

Figure 2

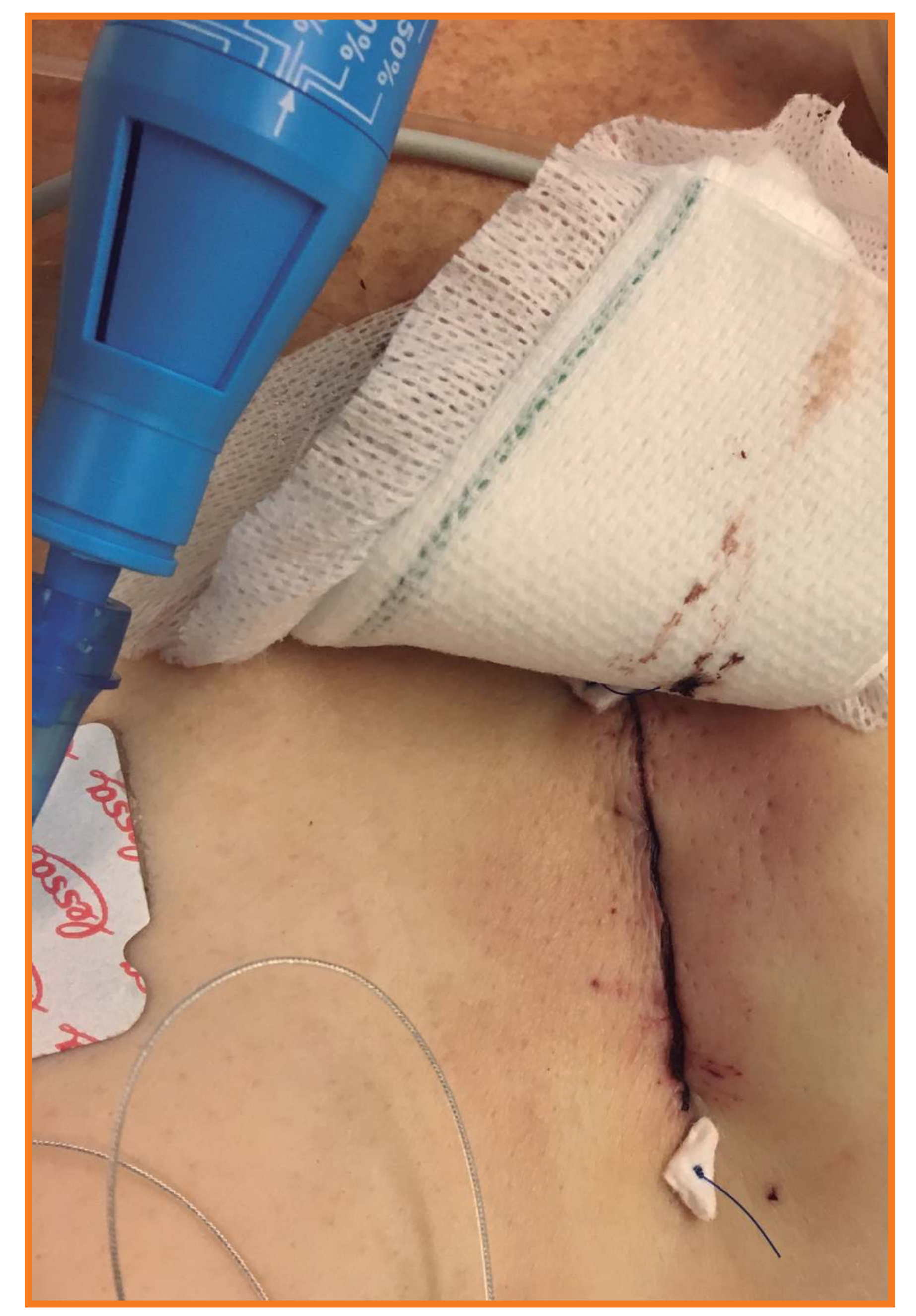

Figure 3

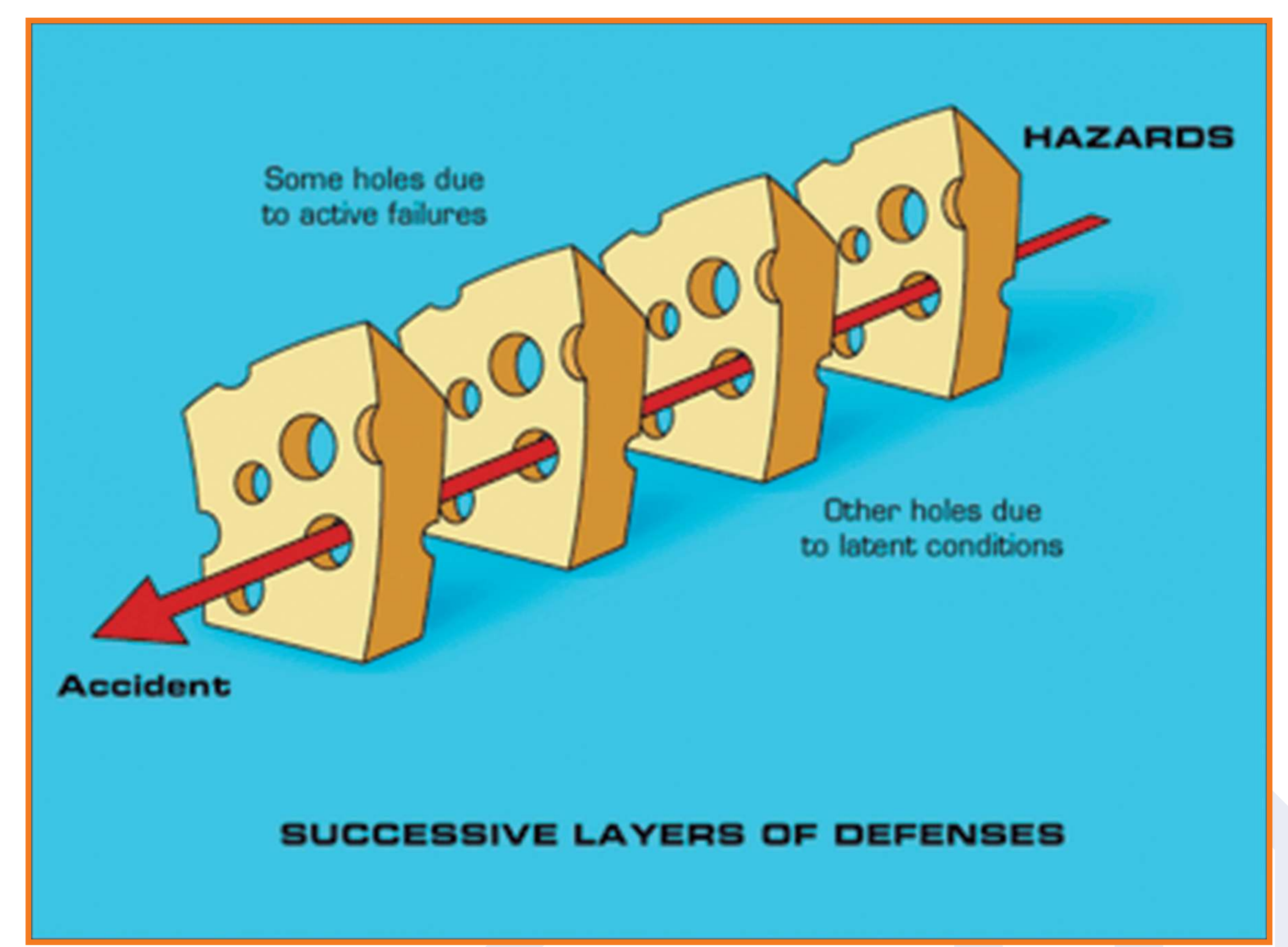

To err is human. When you are treating human beings, you can't afford to make a mistake. In Health, to avoid harming the patient, we use "Sucessive Layers of Defense", as James Reason published years ago (Figure 3) (2).

In our Hospital, these layers are: doing a checklist, the swabs and surgical instruments counting,... among others, but the nurses were allowed to use swab $X$ ray detectable to do the wound dressings (except in orthopaedic surgery).

Since this incident, the Hospital changed the wound dressing normative, so now is forbidden to use swab $\mathrm{x}$ ray detectable for all the dressings.

\section{Bibliography}

1. Mahran MA et al. The recurring problem of retained swabs and instruments. Best Pract Res Clin Obstet Gynaecol. 2013 Aug;27(4):489-95

2. Reason, James. Human error: models and management. BJM. 1995. 